\title{
Pencapaian Program Pemindahan Ilmu Tatacara Menyelamat Sewaktu Banjir Dan Kaedah Pemulihan Dalam Kalangan Komuniti Kuala Krai, Kelantan, Malaysia
}

\author{
Yazid Saleh $^{1^{*}}$, Hanifah Mahat ${ }^{2}$, Mohmadisa Hashim ${ }^{3}$, Nasir Nayan ${ }^{4}$, Koh Liew \\ See ${ }^{5}$
}

${ }^{1}$ Fakulti Sains Kemanusiaan

Universiti Pendidikan Sultan Idris,Perak, MALAYSIA

${ }^{2}$ Fakulti Sains Kemanusiaan

Universiti Pendidikan Sultan Idris,Perak, MALAYSIA

${ }^{3}$ Fakulti Sains Kemanusiaan

Universiti Pendidikan Sultan Idris,Perak, MALAYSIA

${ }^{4}$ Fakulti Sains Kemanusiaan

Universiti Pendidikan Sultan Idris,Perak, MALAYSIA

${ }^{5}$ Fakulti Sains Kemanusiaan

Universiti Pendidikan Sultan Idris,Perak, MALAYSIA

* Corresponding Author : yazid@fsk.upsi.edu.my

DOI: https://doi.org/10.30880/jts.2018.10.01.004

\begin{abstract}
Implementation of the knowledge transfer programme on rescue procedures during flood and recovery methods is one of the initiative steps of Universiti Pendidikan Sultan Idris, Kuala Krai District and Land Office, and Ministry of Higher Education to raise the knowledge and awareness of the community in applying rescue procedures during flood and able to recover their lives after flooding events. The knowledge regarding rescue procedures was gradually transferred from the academics to the Graduate Intern (GI), village heads and team members of ResQ UPSI and subsequently the knowledge transfer from the GI to the village community was conducted with the help of rescue procedure module as a guide for the community preparation in dealing with flooding events and management module as well as the construction of instant shelters/houses. The effectiveness of this programme was evaluated based on the knowledge acquired by the community before and after the implementation of the programme. The results of the survey showed an increase in the number of community that has mastered rescue procedure knowledge ( 81 percent), knowledge on the use of first aid kit for emergency aid (83 percent) and knowledge of shelter construction (57 percent) after taking part in the knowledge transfer programme. In conclusion, this programme has benefitted the Kuala Krai community in enhancing the knowledge and awareness regarding rescue procedures, emergency aid and shelter construction to mitigate the impact of floods.
\end{abstract}

Keywords: Knowledge Transfer, Jajahan Kuala Krai, Rescue Procedure, Construction of Shelter 
(C) Universiti Tun Hussein Onn Malaysia Publisher's Office

\section{JTS}

http://penerbit.uthm.edu.my/ojs/index.php/jts
Journal of Techno Social

\section{Pendahuluan}

Kejadian banjir sememangnya mendatangkan pelbagai kesan negatif kepada manusia terutama dalam kemusnahan harta benda, melumpuhkan ekonomi dan ancaman nyawa manusia. Banjir merupakan bencana alam dan komponen penting dalam kitaran semula jadi yang sering berlaku dalam pelbagai cara dan mampu menenggelamkan kawasankawasan rendah yang didiami penduduk (Mmom \& Aifesehi, 2013). Banjir boleh terjadi apabila air sungai lebihan melimpah dari tebing sungai dan limpahan ini berlaku akibat hujan lebat tanpa berhenti untuk tempoh beberapa hari di lokasi-lokasi tertentu (Tuan Pah Rokiah, Abd Rahim, \& Hamidi, 2014).Secara umumnya, banjir adalah bencana semula jadi yang sering melanda kebanyakan negara seperti Bangladesh, India, Thailand, Myanmar dan termasuk Malaysia akibat faktor iklim dan aktiviti manusia. Menurut Stanley (2000), kejadian banjir berlaku secara berperingkat di mana peringkat pertama adalah satu ancaman dan amaran kepada masyarakat bahaya yang akan datang, peringkat kedua adalah kecemasan atau krisis apabila masyarakat berkongsi kesan dan penderitaan, peringkat ketiga adalah sama ada kelegaan atau kemerosotan dan peringkat keempat adalah pemulihan atau kemusnahan. Walau bagaimanapun, peringkat pertama merupakan fasa paling penting dalam membuat persediaan menghadapi bencana banjir dan bertindak dalam misi menyelamat mangsa-mangsa banjir yang mendiami kawasan mudah ditenggelami banjir. Hal ini kerana masyarakat sepatutnya berwaspada pada amaran bencana banjir yang bakal berlaku bagi tujuan mengurangkan kesan bencana terhadap manusia dan mengurangkan kemusnahan harta benda pada ketika itu. Begitu juga pada peringkat ketiga yang merupakan fasa pemulihan semula kehidupan mangsa banjir yang terjejas banjir.

Namun begitu, kesedaran komuniti terhadap langkah-langkah persediaan untuk menghadapi bencana banjir seperti penggunaan alatan keselamatan dan kemahiran menyelamat sangatlah rendah lebih-lebih lagi jika berlaku banjir yang berskala besar kerana banjir sedemikian mampu meningkatkan kerosakan harta benda dan tempat perlindungan serta mengancam nyawa manusia. Seperti mana dinyatakan oleh M. Shah (2008) dan Rahman, Haque, Khan, Salehin dan Bala (2005), kejadian bencana banjir ekstrem yang berlaku secara berpanjangan mampu menyebabkan kerosakan yang lebih tinggi berlaku. Oleh itu, program pemindahan ilmu tatacara menyelamat sewaktu banjir dan kaedah pemulihan dilaksanakan bagi meningkatkan kesedaran komuniti tentang tatacara menyelamat ketika banjir berskala besar berlaku dan memulihkan semula kehidupan komuniti yang terjejas teruk. Dengan pelaksanaan program ini, tatacara menyelamatkan mangsa ketika banjir dan kaedah pemulihan boleh diterapkan dalam kalangan komuniti terutama yang mendiami kawasan yang berisiko menghadapi banjir setiap tahun. Hal ini kerana program pemindahan ilmu merupakan salah satu langkah untuk membentuk masyarakat berpengetahuan dan berkemahiran menerusi medium pendidikan yang perlu diperluaskan kepada komuniti. Dengan itu, kertas kerja ini akan membincangkan tentang pencapaian program pemindahan ilmu tatacara menyelamat dan kaedah pemulihan dalam kalangan komuniti Kuala Krai, Kelantan terutamanya Kampung Manjor, Laloh dan Sungai Rek.

\section{Latar Belakang Program Pemindahan Ilmu}

Di Malaysia, negeri Kelantan merupakan salah satu negeri yang sering dilanda banjir kerana Kelantan antara negeri yang terdedah kepada hujan monsun timur laut pada setiap tahun. Dengan keadaan negeri Kelantan yang terletak di Pantai Timur Semenanjung Malaysia telah menyebabkan beberapa kawasan di Kelantan dilanda banjir terutamanya Kuala Krai akibat daripada penerimaan hujan yang lebat ketika monsun timur laut pada bulan November hingga Mac (Rajah 1a). Berdasarkan kejadian banjir terkini di Kuala Krai, banjir paling besar melanda Kuala Krai adalah pada tahun 2014 yang dikenali sebagai "Bah Kuning” (Wan Nur Tasnim, Nor Hidayati, \& Mohammad Nazir, 2015; Kamarul Aryffin et al., 2015). Pada tahun tersebut, Kuala Krai merupakan jajahan yang paling teruk terjejas jika dibandingkan dengan kawasan lain. Ketinggian air banjir pada ketika itu mencecah 5 hingga 10 meter yang mampu menenggelamkan bangunan tingkat 3 dan 4 (Nor Eliza, Hazim, Wan, \& Zulkifli, 2016). Rajah 1b menunjukkan liputan kawasan banjir di Jajahan Kuala Krai pada tahun 2014. Kejadian tersebut telah menyebabkan 202,000 orang mangsa banjir dipindahkan ke pusat pemindahan akibat daripada kenaikan paras air Sungai Kelantan (Kamarul Aryffin et al., 2015). Keadaan ini berisiko mengancam nyawa manusia dan membawa kepada kemudahan harta benda dan tempat berlindung. 


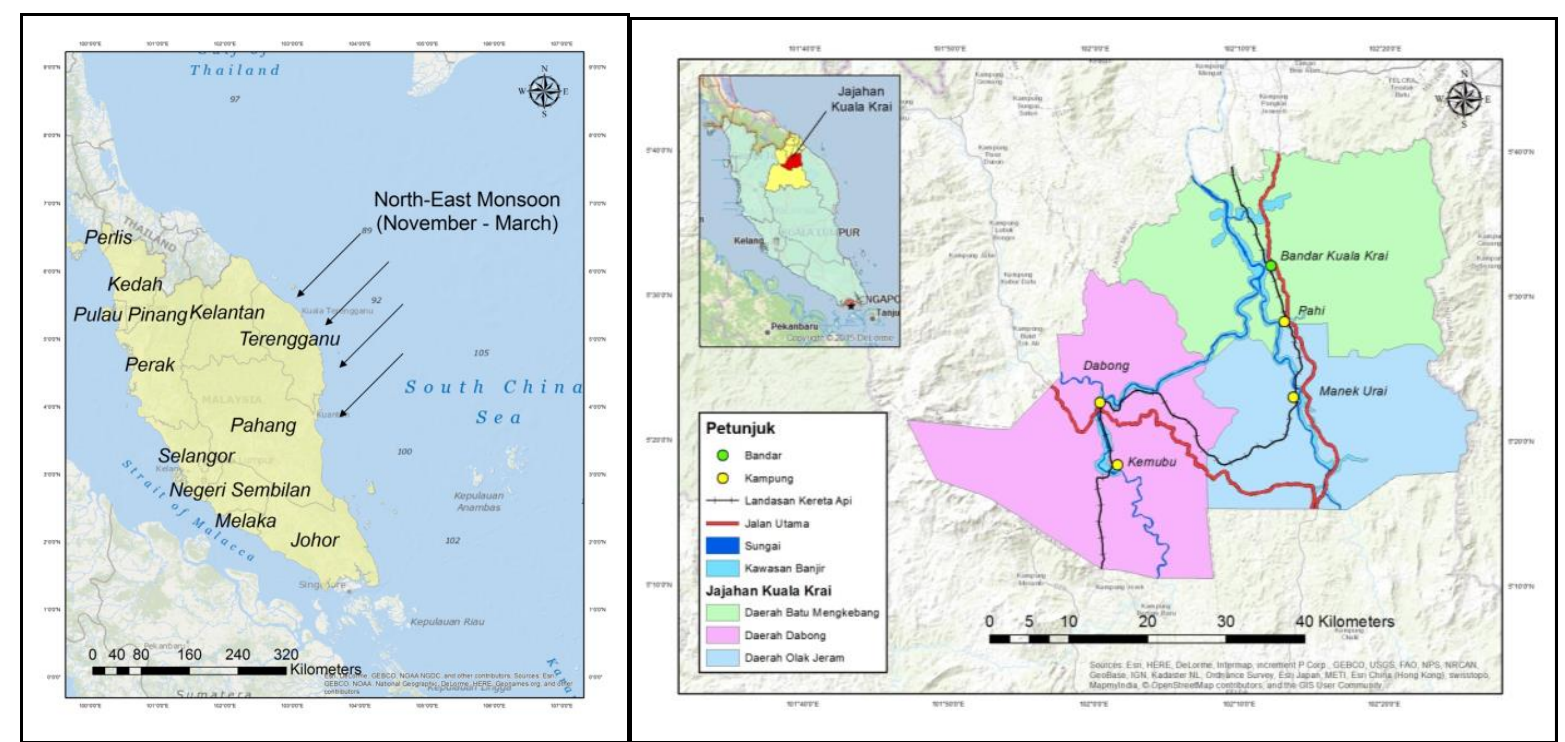

Rajah 1 (a) Kawasan terdedah kepada hujan monsun timur laut pada bulan November hingga Mac dan (b) Liputan kawasan banjir pada tahun 2014 di Jajahan Kuala Krai

Fenomena banjir yang kerap melanda ini menyebabkan komuniti Kuala Krai perlu membuat persediaan awal terhadap misi menyelamat ketika banjir berlaku sebagai langkah berjaga-jaga jika kejadian bencana berulang dan berlaku tanpa diduga. Ekoran daripada kejadian banjir berskala besar pada tahun 2014 di Jajahan Kuala Krai telah membawa kepada pelaksanaan program pemindahan ilmu tatacara menyelamat dan kaedah pemulihan terutama kepada komuniti yang tinggal di kawasan berisiko terkesan banjir Kampung Manjor, Laloh dan Sungai Rek. Pemindahan ilmu adalah satu fokus utama dalam meningkatkan amalan pendidikan (Huberman, 1990; Love, 1985; Willmott, 1994). Program ini telah mula dilaksanakan pada bulan Disember 2015 hingga Disember 2017 bagi menyampaikan ilmu sepenuhnya kepada Graduate Intern (GI), staf Pejabat Tanah dan Jajahan Kuala Krai (PTJKK) dan komuniti Kuala Krai. Tujuan pelaksanaan program ini adalah untuk meningkatkan kesedaran komuniti tentang tatacara menyelamat ketika banjir. Oleh itu, menerusi program ini dapat mendidik komuniti dan memberi pendedahan langsung mengenai langkah-langkah persediaan menghadapi bencana banjir agar komuniti mahir dan berilmu tentang pentingnya pengambilan langkah keselamatan ketika proses menyelamat.

\subsection{Metodologi}

Metod yang digunakan dalam melaksanakan program ini adalah kaedah lapangan iaitu pengedaran soal selidik. Program ini telah dilaksanakan di Kuala Krai terutamanya Kampung Manjor, Laloh dan Sungai Rek (Rajah 2). Hal ini kerana Kuala Krai merupakan antara jajahan di Kelantan yang sering dilanda banjir setiap tahun pada musim tengkujuh. Kawasan yang sering terdedah kepada banjir adalah Bandar Kuala Krai, Pahi, Manek Urai, Lela Jasa dan Dabong kerana kawasan ini merupakan kawasan rendah yang terletak di sepanjang sungai iaitu Sungai Lebir, Sungai Galas dan Sungai Kelantan. Kejadian banjir yang berlaku dipengaruhi oleh faktor hujan lebat pada musim tengkujuh dan menyebabkan berlaku limpahan air sungai.

Pengedaran borang soal selidik telah dilakukan untuk menilai pencapaian program pemindahan ilmu tatacara menyelamat dan kaedah pemulihan yang telah dilaksanakan berdasarkan pengukuran perubahan pengetahuan komuniti. Menurut Argote dan Ingram (2000), pencapaian sesebuah program pemindahan ilmu boleh diukur berdasarkan perubahan pengetahuan atau perubahan prestasi. Item soal selidik terdiri daripada latar belakang responden, pengetahuan tatacara menyelamat, penggunaan peti ubat dan pembinaan shelter. Seramai 100 orang responden telah terlibat dalam kajian tinjaun ini yang merupakan peserta yang menyertai program pemindahan ilmu tatacara menyelamat dan kaedah pemulihan terutama daripada Kampung Manjor (14 orang), Kampung Laloh (20 orang), Kampung Sungai Rek (44 orang) dan lain-lain kampong (22 orang). 


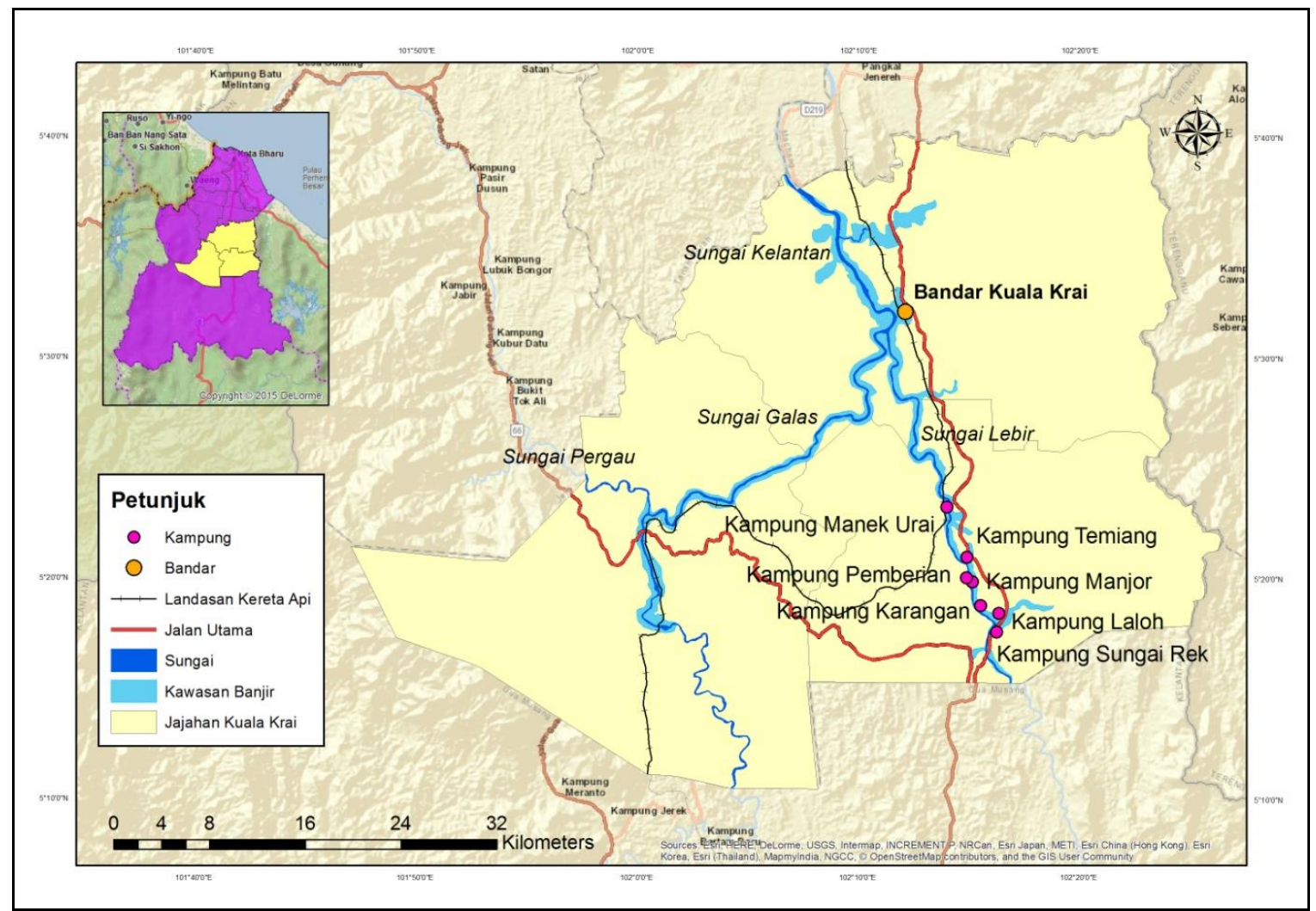

Rajah 2 : Kawasan pelaksanaan program

Pelaksanaan program pemindahan ilmu dilaksanakan secara berperingkat melibatkan teori dan latihan praktikal di sungai dan daratan. Pada fasa permulaan, ilmu telah dipindahkan daripada ahli akademik kepada GI, ketua-ketua kampung dan ahli kumpulan ResQ UPSI. Kemudian diikuti pemindahan ilmu daripada GI kepada komuniti kampung dengan bantuan modul latihan tatacara menyelamat (Rajah 3a) dan modul pengurusan dan pembinaan shelter/rumah segera (Rajah 3b). Pengagihan modul tersebut adalah untuk memberi panduan kepada masyarakat untuk menerapkan tatacara menyelamat dan mengurangkan kesan banjir apabila banjir berskala besar melanda dan meningkatkan kemahiran asas dalam pengurusan rumah segera. Ilmu tatacara menyelamat yang dipindahkan meliputi asas keselamatan arus deras, teknik asas menyelamat, asas pertolongan cemas dan kemahiran asas penyelamat. Sebanyak 100 komuniti telah terlibat dalam program ini yang terdiri daripada Kampung Manjor, Laloh, Sungai Rek, Manek Urai, Karangan dan lain-lain kampung berdekatan kawasan pelaksanaan program.

(a)

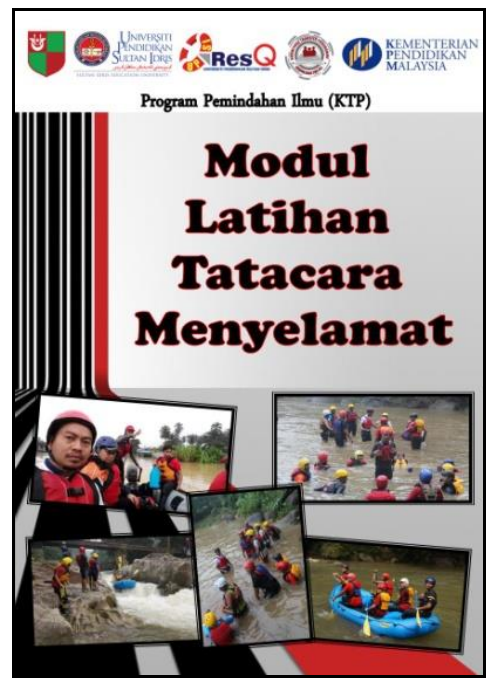

(b)

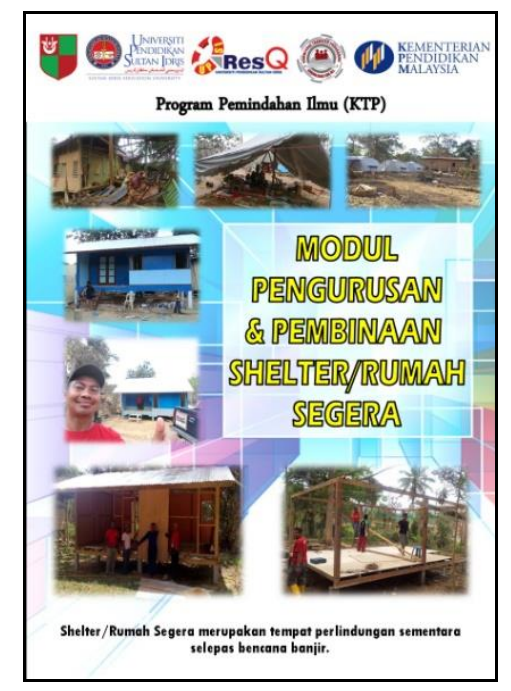

Rajah 3 (a) Modul tatacara menyelamat yang digunakan semasa pemindahan ilmu dan (b) Modul pengurusan dan pembinaan shelter/rumah segera 


\subsection{Dapatan dan Perbincangan}

Berdasarkan profil komuniti yang terlibat dalam program ini menunjukkan majoriti komuniti yang terlibat dalam program pemindahan ilmu adalah daripada Kampung Laloh sebanyak 44 peratus, diikuti lain-lain kampung sebanyak 22 peratus, Kampung Sungai Rek sebanyak 20 peratus dan Kampung Manjor sebanyak 14 peratus. Responden terdiri daripada 81 peratus lelaki dan 19 peratus perempuan. Hasil tinjauan turut mendapati 98 peratus daripada komuniti yang terlibat dalam program adalah komuniti yang tinggal di kawasan dilanda banjir dan 2 peratus komuniti tidak tinggal di kawasan dilanda banjir iaitu Kampung Manjor dan Laloh. Namun begitu, hanya sebanyak 44 peratus sahaja berpengalaman dalam pengurusan banjir, selebihnya 56 peratus tiada pengalaman dalam pengurusan banjir. Tambahan, sebanyak 97 peratus komuniti merupakan mangsa banjir yang dipindahkan ketika banjir melanda. Oleh itu, program pemindahan ilmu adalah releven dilaksanakan bagi meningkatkan pengetahuan dan kesedaran dalam tatacara menyelamat sewaktu banjir dan kaedah pemulihan setelah banjir.

Berdasarkan Jadual 3 menunjukkan perubahan bilangan komuniti dalam penguasaan ilmu menyelamat, penggunaan peti ubat dan pembinaan shelter. Hasil tinjauan sebelum pelaksanaan program, hanya seramai 19 orang sahaja komuniti yang menguasai ilmu tatacara menyelamat. Namun begitu, nilai tersebut telah meningkat kepada 100 orang selepas pelaksanaan program secara teori dan praktikal sebanyak tiga siri. Keadaan ini menunjukkan berlaku peningkatan sebanyak 81 peratus komuniti telah menguasai ilmu tatacara menyelamat. Jelas menunjukkan bahawa pelaksanaan program pemindahan ilmu ini telah meningkatkan kesedaran komuniti tentang tatacara menyelamat ketika banjir terutama dalam penguasaan ilmu asas keselamatan arus deras, teknik asas menyelamat dan kemahiran asas menyelamat.

Dalam aspek penguasaan ilmu penggunaan peti ubat pula mendapati hanya seramai 17 orang sahaja komuniti yang mempunyai ilmu penggunaan peti ubat sebelum program dilaksanakan. Nilai ini telah meningkat kepada 100 orang selepas melibatkan diri dalam program pemindahan ilmu iaitu bengkel pertolongan cemas. Keadaan ini menunjukkan berlaku peningkatan sebanyak 83 peratus komuniti telah menguasai ilmu penggunaan peti ubat semasa pertolongan cemas ketika banjir. Peningkatan peratusan ini telah membuktikan bahawa pelaksanaan program pemindahan ilmu memberi kesan terhadap pertambahan ilmu penggunaan peti ubat terutama ketika melakukan pertolongan cemas bagi membantu menyelamatkan nyawa mangsa, mengelakkan mangsa daripada mengalami kecederaan yang lebih teruk dan membantu mengurangkan kesakitan mangsa.

Dalam perubahan bilangan komuniti dalam penguasaan ilmu pembinaan shelter pula hanya mencatat seramai 18 orang komuniti menguasai ilmu pembinaan shelter sebelum pelaksanaan program. Namun, nilai ini telah meningkat kepada 75 orang setelah komuniti mengikuti program ini. Keadaan ini menunjukkan berlaku peningkatan sebanyak 57 peratus komuniti menerima manfaat daripada pelaksanaan program ini dalam menguasai ilmu pembinaan shelter. Jelas menunjukkan bahawa peningkatan peratusan telah meningkatkan ilmu dan kesedaran komuniti dalam pentingnya kaedah pemulihan selepas banjir supaya dapat membina semula kehidupan selepas bencana banjir besar melanda..

\section{Jadual 3 : Perubahan bilangan komuniti dalam penguasaan ilmu menyelamat, penggunaan peti ubat dan} pembinaan shelter

$\begin{array}{ll}\text { Ilmu yang dipindahkan } & \begin{array}{l}\text { Sebelum program } \\ \text { (orang) }\end{array}\end{array}$

(orang)

Tatacara menyelamat

Penggunaan peti ubat

Pembinaan shelter
19

17

18
100

100

75
$81 \%$

$83 \%$

$57 \%$

Hasil tinjauan menunjukkan bahawa pemindahan ilmu tatacara menyelamat, penggunaan peti ubat dan pembinaan shelter mengalami perubahan peratusan yang besar iaitu melebihi 50 peratus selepas menyertai bengkel dan simulasi yang dilaksanakan melalui program pemindahan ilmu. Perubahan ini jelas menggambarkan bahawa pencapaian program sedemikian adalah sangat baik dan berkesan meningkatkan pengetahuan mangsa banjir dalam penguasaan ilmu tatacara menyelamat, penggunaan peti ubat dan pembinaan shelter melalui penyampaian ilmu secara teori dan latihan praktikal di sungai. Jelas Zhang dan He (2015) di mana peningkatan kesedaran dapat membantu dalam 
mencapai pemindahan pengetahuan yang berkesan dalam sesuatu projek. Oleh itu, pemindahan ilmu adalah satu fokus utama dalam meningkatkan amalan pendidikan (Huberman, 1990; Love, 1985; Willmott, 1994). Jelas Becheikh et al. (2010) juga, pemindahan ilmu juga adalah inisiatif untuk menyelesaikan masalah-masalah tertentu. Secara tidak langsung, ilmu yang dipindahkan kepada komuniti Kuala Krai dapat dimanfaatkan apabila berlaku banjir ketika musim tengkujuh bagi mengurangkan kesan kejadian banjir terutama dalam aspek keterancaman nyawa dan kehilangan tempat berlindung. Dengan pelaksanaan program sedemikian mampu membawa kepada melahirkan masyarakat yang berdaya tahan apabila dilanda banjir besar dan menyumbang kepada wujudnya masyarakat yang lestari.

\subsection{Kesimpulan}

Secara rumusannya, program pemindahan ilmu tatacara menyelamat dan kaedah pemulihan telah meningkatkan pengetahuan dan kesedaran komuniti Kuala Krai. Situasi ini dapat dibuktikan dengan peningkatan peratusan komuniti dalam penguasaan ilmu yang dipindahkan pada sebelum dan selepas pelaksanaan program di mana ilmu tatacara menyelamat sebanyak 81 peratus, penggunaan peti ubat sebanyak 83 peratus dan pembinaan shelter sebanyak 57 peratus. Dengan itu, pelaksanaan program pemindahan ilmu secara berperingkat ini sangat berkesan dalam meningkatkan kesedaran dan pengetahuan komuniti Kuala Krai terutama ilmu menyelamat dan pertolongan cemas sewaktu banjir dengan bantuan modul latihan tatacara menyelamat sebagai panduan komuniti melakukan persediaan menghadapi banjir. Begitu juga dengan pemindahan ilmu pembinaan shelter dapat meningkatkan kemahiran dan pengetahuan asas mengenai pengurusan shelter dengan bantuan modul pengurusan dan pembinaan shelter/rumah shelter. Penguasaan ilmu ini secara tidak langsung boleh mengurangkan ancaman nyawa manusia semasa bencana banjir melanda dan mengembalikan semula kehidupan mangsa banjir selepas banjir.

\section{Penghargaan}

Terima kasih kepada Kementerian Pelajaran Tinggi dalam menyediakan dana program pemindahan ilmu (Kod projek: 057007-2015-005-01) bagi menjalankan program pemindahan ilmu tatacara menyelamat ketika banjir dan kaedah pemulihan.

\section{Rujukan}

Argote, L., \& Ingram, P. (2000). Knowledge transfer: A basis for competitive advantage in firms. Organizational behavior and human decision processes, 82(1), 150-169.

Becheikh, N., Zaim, S., Idrissi, O., Castonguay, Y., \& Landry, R. (2010). How to improve knowledge transfer strategies and practices in education? Answers from a systematic literature review. Research in Higher Education Journal, 7(1), 1-21.

Huberman, M. (1990). Linkage between researchers and practitioners: A qualitative study. American Educational Research Journal, 27(2), 363-391.

Kamarul Aryffin, B., Shaik Farid, A. W., Nik Hisamuddin, N. A. R., Nik Arif, N. M., Tuan Hairulnizam, T. K., Abu Yazid, M. N., \& Mohd Roslani, A. M. (2015). The record-setting flood of 2014 in Kelantan: Challenges and recommendations from an emergency medicine perspective and why the medical campus stood dry. Malaysia Journal of Medical Sciences, 22(2), 1-7.

Love, J. M. (1985). Knowledge transfer and utilization in education. Review of Research in Education, 12(1), 337-386.

M. Shah, A. K. (2008). Disaster preparedness for sustainable development in Bangladesh. Disaster Prevention and Management: An International Journal, 17(5), 662-671.

Mmom, P. C., \& Aifesehi, P. E. (2013). Impact of the 2012 flood on water quality and rural livelihood in the Orashi Province of the Niger Delta, Nigeria. Journal of Geography and Geology, 5(3), 216-225.

Nor Eliza, A., Hazim, M., Wan, Y. C., \& Zulkifli, Y. (2016). Rainfall analysis of the Kelantan Big Yellow Flood 2014. Jurnal Teknologi, 78(9-4), 83-90.

Rahman, M. R., Haque, A., Khan, M. S. A., Salehin, M., \& Bala, S. K. (2005). Investigation of hydrological characteristics of flood 2004 with special emphasis on Dhaka City, Institute of Water and Flood Management, Bangladesh University of Engineering and Technology, Dhaka. 
Stanley, G. J. K. (2000). Disaster management and social development. Internatinal Journal of Sociology and Social Policy, 20(7), 66-81.

Tuan Pah Rokiah, S. H., Abd Rahim, M. N., \& Hamidi, I. (2014). The level of satisfaction towards flood management system in Kelantan, Malaysia. Pertanika Journal of Social Science and Humanities, 22(1), 257-269.

Wan Nur Tasnim, W. H., Nor Hidayati, Z., \& Mohammad Nazir, A. (2015). Knowledge sharing and lesson learned from flood disaster: A case in Kelantan. Journal of Information Systems Research and Innovation, 9(2), 1-10.

Willmott, H. (1994). Management education: Provocations to a debate. Management Learning, 25(1), $105-136$.

Zhang, L., \& He, J. (2015). Critical factors affecting tacit-knowledge sharing within the integrated project team. Journal of Management in Engineering, 32(2), Article number 04015045 (in Press). 